\title{
Preparation and Characterization of Waterborne Polyurethaneurea Composed of Dimer Fatty Acid Polyester Polyol
}

\author{
Lin Jiang, ${ }^{1,2}$ Qiang $\mathrm{Xu}^{1,2}$ and Chun $\mathrm{Pu} \mathrm{Hu}{ }^{1,2}$ \\ ${ }^{1}$ Key Laboratory for Ultrafine Materials, Ministry of Education, Shanghai 200237, China \\ ${ }^{2}$ School of Materials Science and Engineering, East China University of Science and Technology, Shanghai 200237, China
}

Received 9 November 2005; Accepted 2 February 2006

Recommended for Publication by Alan Fuchs

\begin{abstract}
A series of polyurethaneurea (PUU) aqueous dispersions, which were stable at ambient temperature for more than 1 year, were prepared with $\mathrm{C}_{36}$-dimer-fatty-acid-based polyester polyol, isophorone diisocyanate, dimethylol propionic acid, and ethylenediamine. The particle size of all these PUU (DPU) aqueous dispersions $(<100 \mathrm{~nm})$ was less than that of comparable specimens, that is, poly-(neopentyl glycol adipate) polyester-polyol-based PUU (APU) aqueous dispersions, and the polydispersity index was very narrow $(\leq 1.13)$. The films prepared with the DPU aqueous dispersions exhibited excellent waterproof performance, such as low amount of water absorption ( $1.3 \mathrm{wt} \%$ ), and good mechanical properties (hardness and tensile strength), resulting from the strong hydrogen bonding in urea carbonyl groups and the perfect ordered structure of hard segments compared with those prepared with the APU aqueous dispersions. The surface hydrophobicity of the films prepared with modified DPU aqueous dispersions, which were modified with a fluorinated polyacrylate emulsion, was excellent, as the water contact angle on the surface of such films rose up to 100. The mechanical properties of such modified DPU films were further enhanced.
\end{abstract}

Copyright (C) 2006 Lin Jiang et al. This is an open access article distributed under the Creative Commons Attribution License, which permits unrestricted use, distribution, and reproduction in any medium, provided the original work is properly cited.

\section{INTRODUCTION}

Waterborne polyurethane (PU) and PUU are widely used in coatings and adhesives since they are nontoxic and environmental. However, most of the waterborne PU and PUU are prepared with a self-dispersion method, and their films usually exhibit undesirable water-resistance performance because of the existence of the hydrophilic units into the macromolecular chains. It is well known that the PU or PUU is a block copolymer consisting of soft and hard segments alternatively. Thus, the water resistance and mechanical properties of the waterborne PU and PUU films can be enhanced by varying the structure of the soft and hard segments in PU or PUU. B. K. Kim and T. K. Kim [1] prepared a waterborne PU with a mixture of difunctional poly(tetramethylene adipate) polyol and difunctional poly(propylene oxide) polyol (PPG) as soft segment, and found that the PU film with a higher PPG content displayed better mechanical properties. Lee et al. [2] found that a waterborne PU film prepared from a polyol with higher molecular weight showed poorer water-resistance property. Hourston et al. [3] found that or- ganic solvent resistance performance for a waterborne PU film prepared with difunctional poly(tetramethylene oxide) polyol was better than that prepared with difunctional PPG. Y. S. Hu et al. [4] prepared a waterborne PUU with castor oil (a renewable material), PPG, or mixture of castor oil/PPG, and the morphologies and the mechanical properties of their films were observed and studied. Yang et al. [5] prepared a series of polyester-based waterborne PUUs with well-defined hard segments, and found that the waterproof and mechanical properties for these PUU films were enhanced significantly.

Recently, Honcoop and Appelman [6] reported that a waterborne $\mathrm{PU}$ could be prepared with a $\mathrm{C}_{36}$-dimer-fattyacid based polyester polyol (DFA) and exhibited good mechanical properties, but the relationship between the morphologies and properties for such a new kind of material has not been reported yet. In this paper, a series of PUU aqueous dispersions based on DFA were prepared, and the effect of this special soft segment on the physical properties of such PUU aqueous dispersions and their films was observed. The experimental results indicate that the water resistance 


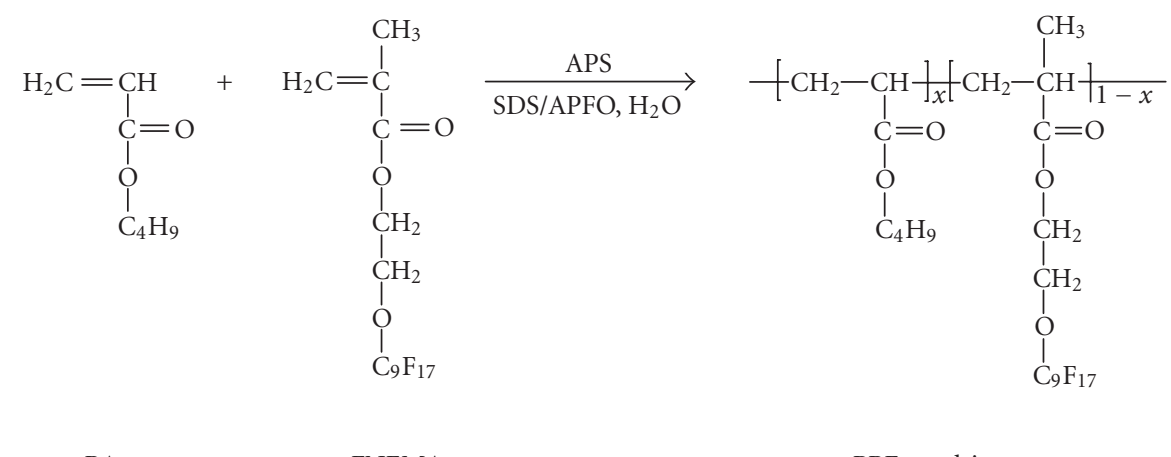

BA

FNEMA

PBF emulsion

Scheme 1: Preparation of fluorinated polyacrylate emulsion.

and mechanical properties of this kind of PUU film are enhanced appreciably, and the water-absorbing amount of the waterborne PUU film with $35 \mathrm{wt} \%$ of hard segment is as low as $1.3 \mathrm{wt} \%$. Furthermore, the PUU aqueous dispersions based on DFA and modified with a fluorinated polyacrylate emulsion were also prepared, and it is found that the water repellence property and the mechanical properties of their films are further enhanced.

\section{EXPERIMENTAL}

\subsection{Materials}

$\mathrm{C}_{36}$-dimer-fatty-acid-based difunctional polyester polyol (Priplast 3192, industrial product, hydroxyl number = $56 \mathrm{mgKOH} / \mathrm{g}$ ) was produced by Uniqema Co, England, and was dried under vacuum at $110^{\circ} \mathrm{C}$ for 1 hour. Difunctional polyester polyol made with neopentyl glycol and adipate acid (PNA, industrial product, hydroxyl number $=56 \mathrm{mgKOH} / \mathrm{g}$ ) was provided by Qingdao Yutian Chemical Plant, and was dried under vacuum at $110^{\circ} \mathrm{C}$ for 1 hour. Dimethylol propionic acid (DMPA, industrial product) was produced by Perstop Co. and was dried at $60^{\circ} \mathrm{C}$ for 24 hours under vacuum. Isophorone diisocyanate (IPDI, industrial product) was produced by Huls Co. The other chemicals were laboratory reagents and were purchased from different manufacturers. $\mathrm{N}$-methylpyrrolidone (NMP) and triethylene amine (TEA) were dried with $4 \AA$ molecular sieves for one week before use, and the others were used as received.

The fluorinated polyacrylate (PBF) emulsion composed of butyl acrylate (BA) and 2-[(perfluorononeny1)oxyl] ethyl methacrylate (FNEMA) was prepared with ammonium persulfate (APS) as initiator and sodium lauryl sulfate/ammonium perfluorooctante (SDS/APFO) as a complex emulsifier in water. Such an emulsion had a solid concentration of $15.5 \mathrm{wt} \%$. The preparation process of the PBF emulsion was briefly described elsewhere [7], and is shown in Scheme 1.

\subsection{Preparation of PUU aqueous dispersion}

A calculated amount of DFA or PNA, DMPA, NMP, and IPDI were charged into a $250 \mathrm{~mL}$ four-necked, round-bottom flask equipped with a mechanical stirrer, an inlet of dry nitrogen, a condenser, and a thermometer. This mixture was then heated to $80^{\circ} \mathrm{C}$ for $3-4$ hours until the theoretical NCO content was reached. The NCO-terminated prepolymer was neutralized by adding TEA at $50^{\circ} \mathrm{C}$ for 30 minutes, and then dispersed into deionized water under vigorous stirring at $40^{\circ} \mathrm{C}$. PUU aqueous dispersions with different HS contents were prepared after the chain extension by the dropwise addition of ethylenediamine. All the PUU aqueous dispersions had a solid content of $33 \mathrm{wt} \%$. For simplicity, the PUUs prepared with DFA or PNA were called DPU-X or APU-X : X is the HS content.

Under vigorous stirring, PBF emulsion was dispersed into the DPU-35 aqueous dispersion to prepare a modified PUU aqueous dispersion. This modified PUU aqueous dispersion was simply called MPU-Y and Y is the fluorinated copolymer content.

PUU films were prepared by casting the aqueous dispersions into a poly(tetrafluoraethylene) mold under $25^{\circ} \mathrm{C}$. The films were dried at $25^{\circ} \mathrm{C}$ for one week and then dried to a constant weight under vacuum at $60^{\circ} \mathrm{C}$.

\subsection{Characterization}

A solution consisting of $5 \mathrm{~g}$ of DFA and $10 \mathrm{~g}$ of NMP was prepared first, and then the molecular structure of DFA was analyzed by an electrospray-ionization mass spectrometer (Micromass LCT KC317). The particle size of the PUU aqueous dispersion was determined by a Mastersizer 2000 particle size analyzer. The viscosity of the aqueous dispersion was measured by a NDJ-79 rotation viscometer at $25^{\circ} \mathrm{C}$ and at a shear rate of $2000 \mathrm{~s}^{-1}$. Zeta potential measurements were performed on a Brookhowen Zeta Potential Analyzer. High-temperature stability of the aqueous dispersion was determined by observing whether the aqueous dispersion was deposited or not after heating to $60^{\circ} \mathrm{C}$ for 40 hours in an oven. For measuring freeze-thaw stability of the aqueous dispersion, the PUU aqueous dispersion was cooled to $-20^{\circ} \mathrm{C}$ for 18 hours and kept at ambient temperature for 6 hours to observe whether the aqueous dispersion deposited or not. The Fourier transform infrared (FTIR) spectra of the PUU films were recorded with 
a Nicolet 5DXC FTIR spectrometer at $25^{\circ} \mathrm{C}$. Wide-angle Xray diffraction (WAXD) measurements were obtained by means of a Rigaku D/Max- $\gamma$ B X-ray diffractometer employing nickel-filtered $\mathrm{CuK} \alpha(1.5418 \AA)$ at an operational voltage of $40 \mathrm{kV}$; the scope of the scan was $3^{\circ}-50^{\circ}$. Differential scanning calorimetry (DSC) was measured with a TA Instruments 2910 modulated DSC analyzer at a heating rate of $10^{\circ} \mathrm{C} / \mathrm{min}$ under a nitrogen atmosphere. The mechanical properties for all the specimens were conducted on an Instron 4465 testing machine at a $50 \mathrm{~mm} / \mathrm{min}$ crosshead rate, and the specimens were made in accordance with GB104079. The hardness of PUU sample was measured according to GB/G1703-93.

The surface tension $(\gamma)$ of the PUU aqueous dispersion was tested using the drop volume method at $25^{\circ} \mathrm{C}$ and can be expressed as follows [8]:

$$
r=\frac{\rho V g}{2 \pi R f}
$$

where $\rho$ is the density of the PUU aqueous dispersion, $g$ is $980 \mathrm{~cm} / \mathrm{s}^{2}, V$ is the volume of the liquid drop, $R$ is the capillary radius, and $f$ is the correction factor. For $0.3<R / V^{1 / 3}<$ $1.2, f$ is equal to $0.9045-0.7249\left(R / V^{1 / 3}\right)+0.4293\left(R / V^{1 / 3}\right)^{2}$.

The amount of the water absorption for the PUU film $(20 \times 20 \times 1 \mathrm{~mm})$ was tested in water at $25^{\circ} \mathrm{C}$ for 24 hours and was calculated as follows:

$$
\text { water absorption }(\%)=\frac{\left(W_{2}-W_{1}\right)}{W_{1}} \times 100 \% \text {, }
$$

where $W_{1}$ and $W_{2}$ are the weights of PUU film before and after soaking, respectively.

The contact angle of a liquid on the film surface was measured with the sessile drop method at $25^{\circ} \mathrm{C}$ with a JC2000A series instrument. The surface energy of the PUU film was calculated as follows [9]:

$$
\begin{aligned}
\left(1+\cos \vartheta_{1}\right) \gamma_{1} & =4\left(\frac{\gamma_{1}^{d} \gamma_{s}^{d}}{\gamma_{1}^{d}+\gamma_{s}^{d}}+\frac{\gamma_{1}^{p} \gamma_{s}^{p}}{\gamma_{1}^{p}+\gamma_{s}^{p}}\right), \\
\left(1+\cos \vartheta_{2}\right) \gamma_{2} & =4\left(\frac{\gamma_{2}^{d} \gamma_{s}^{d}}{\gamma_{2}^{d}+\gamma_{s}^{d}}+\frac{\gamma_{2}^{p} \gamma_{s}^{p}}{\gamma_{2}^{p}+\gamma_{s}^{p}}\right), \\
\gamma_{S} & =\gamma_{S}^{d}+\gamma_{S}^{p},
\end{aligned}
$$

where $\gamma_{s}, \gamma_{s}^{d}$, and $\gamma_{s}^{p}$ are the surface energy, the dispersion component of the surface energy, and the polar component of the surface energy for PUU film, respectively; $\gamma_{1}$, $\gamma_{1}^{d}$, and $\gamma_{1}^{p}$ are the surface tension, the dispersion component of the surface tension, and the polar component of the surface tension for water, respectively $\left(\gamma_{1}^{d}=51.0 \mathrm{mN} / \mathrm{m}\right.$, $\left.\gamma_{1}^{p}=21.8 \mathrm{mN} / \mathrm{m}\right) ; \gamma_{2}, \gamma_{2}^{d}$, and $\gamma_{2}^{p}$ are the surface tension, the dispersion component of the surface tension, and the polar component of the surface tension for ethylene glycol, respectively $\left(\gamma_{2}^{d}=19.0 \mathrm{mN} / \mathrm{m}, \gamma_{2}^{p}=29.3 \mathrm{mN} / \mathrm{m}\right)[9]$.

\section{RESULTS AND DISSCUSSION}

\subsection{Characterization of DFA}

The DFA is a commercial polyester polyol synthesized with dimer fatty acid. It is the only information for this product described in its product data sheet. Thus, the molecular structure of the DFA is not clear, and it is necessary to characterize the DFA for studying the waterborne PUU further. Figure 1 shows the mass spectrum of DFA. It is of interest to find that there are two data sets for ion peaks at mass values of 229, 457, 685, 914, 1142, 1370 and 576, 804, 1032, $1260,1488,1717$ in mass spectrum, respectively. The mass difference of 228 between the two adjacent ionic peaks for each data set can be observed indicating the existence of poly (hexylene adipate) segments in the macromolecular chain of the DFA, as the molecular weight of repeating units in such a segment is just 228. Honcoop and Appelman [6] pointed out that the DFA was synthesized with dimerized acids, which were prepared with some unsaturated fatty acids made from soybean oil or tall oil. The unsaturated fatty acids prepared from the soybean oil or tall oil are mainly composed of the oleic acid and linoleic acid. Since the average molecular weight of the dimerized oleic acid or linoleic acid is around 560 , the strong ion peak appearing at mass of 576 should be assigned to a $\mathrm{C}_{36}$-dimer fatty acid unit. Thus, the DFA is reasonable to be considered for synthesizing with the $\mathrm{C}_{36^{-}}$dimer fatty acid, hexylene glycol, and adipic acid, as consistent with the description of Scholz et al. for DFA in a US patent [10].

\subsection{PUU aqueous dispersions}

$\mathrm{Xu}$ et al. [11] indicated that the stability for waterborne PUU mainly depended on the monomer feed ratio of $[\mathrm{NCO}] /[\mathrm{OH}]$ (molar ratio) in the system during the synthesis process, that is, the PUU aqueous dispersion tended to gelling, if the value of $[\mathrm{NCO}] /[\mathrm{OH}]$ was less than 1.3 , and the aqueous dispersion was not stable with wide particle size distribution, if the value of $[\mathrm{NCO}] /[\mathrm{OH}]$ was more than 2.0. Thus, for preparing a stable waterborne PUU, it is necessary to control the value of $[\mathrm{NCO}] /[\mathrm{OH}]$ from 1.3 to 2.0. A series of PUU aqueous dispersions with different structure of soft segment (DFA or PNA) and HS contents were prepared by adjusting the DMPA content and the values of $[\mathrm{NCO}] /[\mathrm{OH}]$, as shown in Table 1 . Table 1 shows that the particle size of both kinds of PUU aqueous dispersions increases with increasing the HS content, while the DMPA concentration remains constant $(4.0 \mathrm{wt} \%)$. This behavior should be related to the increase of the amount of urea group in the PUU, so as to restrict the activity of macromolecular chains as well as to enlarge the particle size of the aqueous dispersion. This will be discussed further in the following part. Table 1 also shows that the particle size for both kinds of PUU aqueous dispersions decreases and the particle size distribution nearly remains constant with increasing the DMPA concentration. Since the PUU macromolecular chain consists of the hydrophilic 


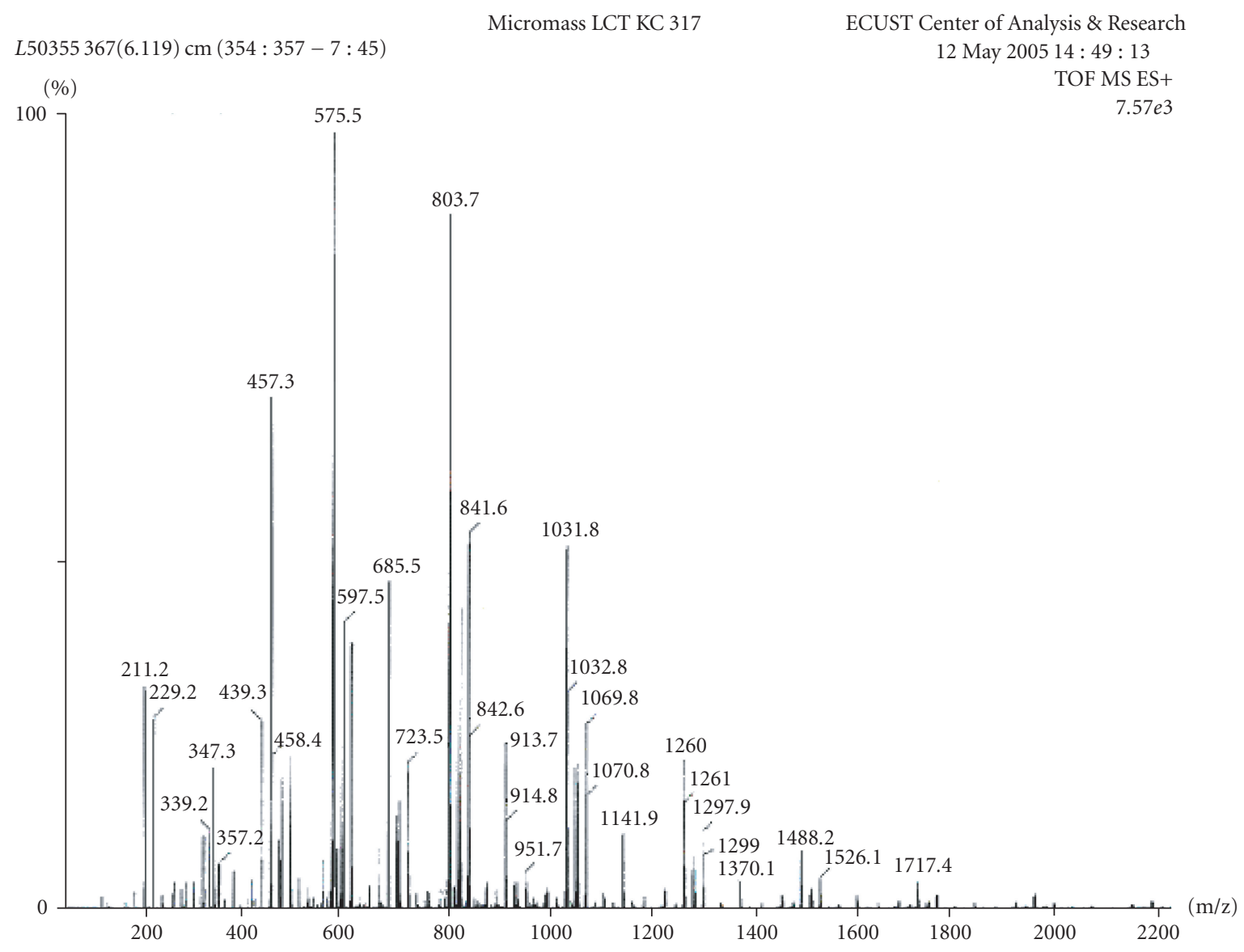

FIgURE 1: Mass spectra of $\mathrm{C}_{36}$-dimer-fatty-acid-based polyester polyol.

TABLE 1: Some physical properties of PUU aqueous dispersions prepared with different polyols. All PUU aqueous dispersions were stable at ambient temperature for more than 1 year, and did not deposit after five freeze-thaw stability tests or high-temperature stability test.

\begin{tabular}{l|ccccccc}
\hline Samples & HS content $(\%)$ & {$[\mathrm{NCO}] /[\mathrm{OH}]$} & $\begin{array}{c}\text { DMPA unit/ } \\
\text { prepolymer }(\%)\end{array}$ & $\begin{array}{c}\text { Particle } \\
\text { size }(\mathrm{nm})\end{array}$ & $\begin{array}{c}\text { Polydispersity } \\
\text { index }\end{array}$ & $\begin{array}{c}\text { Viscosity } \\
(\mathrm{mPa} \cdot \mathrm{s})\end{array}$ & $\begin{array}{c}\text { Surface tension }(\mathrm{mN} / \mathrm{m}) \\
\text { DPU-25 }\end{array}$ \\
\hline DPU-31 & 31 & 1.35 & 4.0 & 60 & 1.13 & 30.5 & 48.0 \\
DPU-35 & 35 & 1.7 & 4.0 & 69 & 1.09 & 20.2 & 48.6 \\
DPU-43 & 43 & 2.0 & 4.0 & 74 & 1.07 & 10.6 & 49.4 \\
DPU-50 & 50 & 2.0 & 6.2 & 63 & 1.05 & 13.4 & 48.3 \\
APU-25 & 25 & 1.35 & 4.0 & 58 & 1.06 & 35.8 & 47.8 \\
APU-31 & 31 & 1.7 & 4.0 & 70 & 1.07 & 25.0 & 47.6 \\
APU-35 & 35 & 2.0 & 4.0 & 72 & 1.07 & 17.0 & 46.7 \\
APU-43 & 43 & 2.0 & 6.2 & 71 & 1.07 & 24.9 & 46.0 \\
APU-50 & 50 & 2.0 & 8.0 & 69 & 1.07 & 36.8 & 45.7 \\
\hline
\end{tabular}

DMPA salt unit (for simplicity, it is only called DMPA unit), the lowering of the particle size of PUU aqueous dispersion with increasing the concentration of the DMPA unit should be expected. The experimental data show that the viscosity of the aqueous dispersion increases with the decrease of the particle size (see Table 1). This is consistent with the previous experimental results for polyurethaneurea/acrylate polymer aqueous dispersions [12], resulting from the increase of hydrodynamic volume of the particles. 
TABLE 2: Some physical properties of PUU aqueous dispersions modified with PBF emulsion. All PUU aqueous dispersions were stable at ambient temperature for more than 1 year, and did not deposit after five freeze-thaw stability tests or high-temperature stability test.

\begin{tabular}{l|ccccc}
\hline Samples & $\begin{array}{c}\text { Fluorinated } \\
\text { copolymer } \\
\text { content }(\%)\end{array}$ & Particle size $(\mathrm{nm})$ & Polydispersity index & Viscosity $(\mathrm{mPa} \cdot \mathrm{s})$ & Surface tension $(\mathrm{mN} / \mathrm{m})$ \\
\hline DPU-35 & 0 & 74 & 1.07 & 10.6 & 49.4 \\
MPU-1 & 1.0 & 79 & 1.08 & 10.0 & $45.4(45.1)^{(\mathrm{b})}$ \\
MPU-3 & 3.0 & 83 & 1.10 & 8.7 & $42.2(41.8)^{(\mathrm{b})}$ \\
MPU-5 & 5.0 & 1.12 & 6.9 & $38.9(38.7)^{(\mathrm{b})}$ \\
\hline
\end{tabular}

(a) The surface tensions in brackets were measured from the DPU-35 dispersion only containing the complex emulsifier.

It is of interest to note that in Table 1, the DPU aqueous dispersion exhibits smaller particle size and higher surface tension than the APU aqueous dispersion containing the same HS content. The particle size of the PUU aqueous dispersion is affected mainly by the content of hydrophilic unit and the flexibility of the macromolecular chain. The macromolecular chain of DPU made with DFA, which was synthesized by $\mathrm{C}_{36}$-dimer fatty acid, hexylene glycol, and adipic acid, has longer segment composed of $-\mathrm{CH}_{2}-$ groups and less methyl side groups than that of APU, resulting in higher chain flexibility. The flexible macromolecular chain in DPU is easy to deform and is favorable to form a smaller particle. It is generally believed that for a waterborne PUU, the DMPA units should stay in the water phase and the hydrophobic soft segments would be enriched on the surface of the aqueous dispersion. In this case, a more compact arrangement of the soft segments in APU system than that in DPU system on the surface of aqueous dispersion could be expected, as the soft segments in APU are more regular than those in DPU. As a result, the surface of the APU aqueous dispersion will be occupied by more soft segments resulting in the lowering of the surface tension. It is also of interest to note that the surface tension for both aqueous dispersion systems (DPU and APU) does not change significantly while the DMPA concentration maintains at $4.0 \mathrm{wt} \%$ (see Table 1). It should be expected that if the DMPA concentration is increased, the surface of the aqueous dispersion would be easy to be covered with soft segments, giving rise to a low surface tension, as the hard segments will be easy to enter into the water phase. In this case, the surface tension of the aqueous dispersion should remain constant at the same concentration of DMPA in the system (4.0 $\mathrm{wt} \%)$.

For enhancing the hydrophobicity of the waterborne PUU further, the DPU aqueous dispersions were modified with PBF emulsion and their physical properties are listed in Table 2. For MPU aqueous dispersions, most of the hydrophobic fluorinated copolymers should be wrapped by the PUU macromolecular chains in the systems and will be discussed further. Thus, the particle size and the particle size distribution of the MPU aqueous dispersions increase in comparison with those of the unmodified one. The viscosity of the modified aqueous dispersion decreases with increasing the particle size resulting from the decrease of the

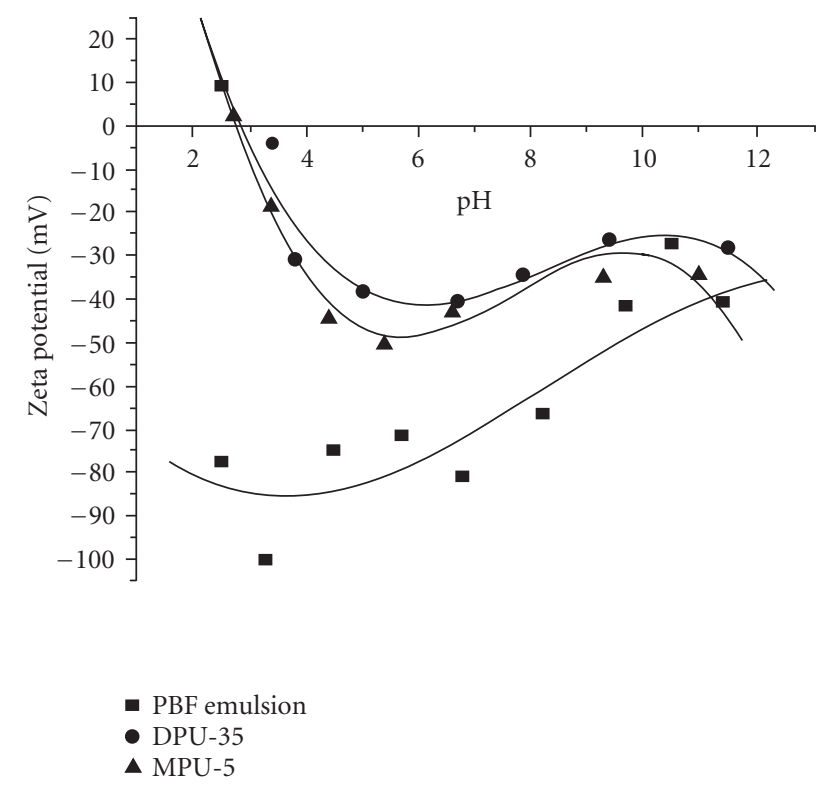

Figure 2: Zeta potential versus $\mathrm{pH}$ value for PBF emulsion and PUU aqueous dispersions.

hydrodynamic volume of the particles. Table 2 shows that the surface tension of MPU aqueous dispersions decreases gradually with the increase of the fluorinated copolymer content. For further studying this behavior, the same content of complex emulsifier (SDS/APFO) existing in the MPU aqueous dispersion was added in the DPU-35 aqueous dispersion and the surface tension of such an aqueous dispersion was tested, as also listed in Table 2. It is of interest to note that the surface tension of the MPU aqueous dispersions is very close to that of relative DPU aqueous dispersion only containing the complex emulsifier. It further confirms that the PUU macromolecular chains wrapped most of the hydrophobic fluorinated copolymers in MPU.

The zeta potential values of the aqueous dispersions were measured, as shown in Figure 2. The values of zeta potential for the PBF emulsion are very low $(-45$ to $-100 \mathrm{mV})$ and the isoelectric point (IEP) is not found indicating that the PBF emulsion exhibits the excellent stability either at acid or at 
TABLE 3: Some physical properties of PUU films prepared with different polyols.

\begin{tabular}{|c|c|c|c|c|c|c|c|}
\hline Samples & HS content (\%) & $\begin{array}{c}\text { DMPA } \\
\text { unit/prepolymer } \\
(\%)\end{array}$ & $\begin{array}{c}\text { Water } \\
\text { absorption } \\
(\mathrm{wt} \%)\end{array}$ & $\begin{array}{l}\text { Contact angle } \\
\text { of water } \\
\text { (degree) }\end{array}$ & $\gamma_{s}(\mathrm{mN} / \mathrm{m})$ & $\gamma_{s}^{d}(\mathrm{mN} / \mathrm{m})$ & $\gamma_{s}^{p}(\mathrm{mN} / \mathrm{m})$ \\
\hline DPU-25 & 25 & 4.0 & 3.3 & 85 & 27.9 & 15.7 & 12.2 \\
\hline DPU-31 & 31 & 4.0 & 2.4 & 86 & 27.2 & 15.2 & 12.0 \\
\hline DPU-35 & 35 & 4.0 & 1.3 & 87 & 26.7 & 14.7 & 12.0 \\
\hline DPU-43 & 43 & 6.2 & 2.8 & 84 & 28.2 & 16.6 & 11.6 \\
\hline DPU-50 & 50 & 8.0 & 8.6 & 82 & 29.4 & 17.6 & 11.8 \\
\hline APU-25 & 25 & 4.0 & 18.5 & 83 & 28.7 & 17.3 & 11.4 \\
\hline APU-31 & 31 & 4.0 & 13.7 & 84 & 28.1 & 16.8 & 11.3 \\
\hline APU-35 & 35 & 4.0 & 9.2 & 85 & 27.5 & 16.6 & 10.9 \\
\hline APU-43 & 43 & 6.2 & 15.8 & 81 & 30.4 & 17.7 & 12.7 \\
\hline APU-50 & 50 & 8.0 & 22.3 & 76 & 32.9 & 21.5 & 11.4 \\
\hline
\end{tabular}

basic condition. The stability of the fluorinated copolymer is a result of extremely strong carbon-fluorine bonds in the system, which protects the carbon-carbon bonds from an attack of medium. Figure 2 shows that the IEP of MPU- 5 system is at around $\mathrm{pH}=2.7$, which is very close to that of DPU-35 system $(\mathrm{pH}=2.8)$. Furthermore, the values of zeta potential of MPU-5 system are very similar to those of DPU-35 system and are significantly more positive than those of PBF system. These results suggest that the surface composition of the MPU particles is similar to that of DPU particles and the DPU macromolecular chain should wrap the fluorinated copolymer in the system.

Tables 1 and 2 also show that all the PUU aqueous dispersions are very stable at ambient temperature and they do not deposit after low- and high-temperature stability tests. This behavior is obviously significant for further application of these aqueous dispersions in industries, such as coatings or adhesives.

\subsection{PUU films}

Table 3 shows some surface properties and the amounts of water absorption for different PUU films. For both kinds of PUU films with $4.0 \mathrm{wt} \%$ concentration of DMPA unit, the water-absorbing amount decreases remarkably with increasing the HS content, but the contact angle of water only increases slightly. When the HS content in DPU or APU system is higher than $35 \%$, the concentration of DMPA unit in these specimens increases with increasing the HS content, giving rise to increase the water-absorbing amount and the value of $\gamma_{s}$, and decrease the water contact angle. The value of $\gamma_{s}$ does not change significantly, as $\gamma_{s}^{p}$ remains almost constant and only $\gamma_{s}^{d}$ a little bit increases. However, it should be pointed out that in all cases, the water-absorbing amount of DPU films is much lower than that of APU films and the DPU-35 film shows the lowest water-absorption behavior (1.3 wt\%) and the highest water contact angle over all specimens studied here. In other words, this sample exhibits the

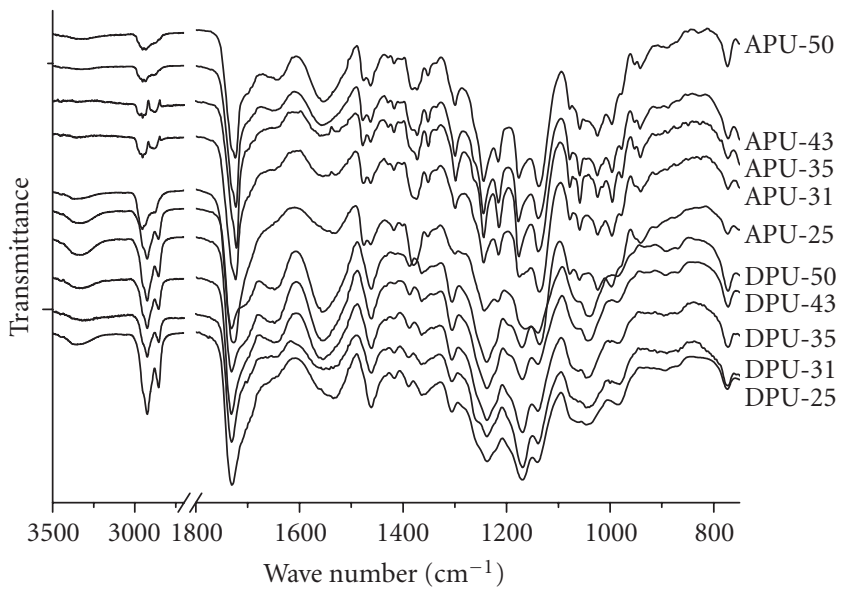

FIGURe 3: FTIR spectra of different PUUs.

best waterproof performance. The water-absorbing amount for both kinds of PUU film increases when the HS content in DPU or APU film is more than 35\%, mainly because the hydrophilicity of these films increases with increasing the concentration of hydrophilic DMPA unit.

In general, the hydrogen bonding directly affects the ordered structure of HS in PUU. Thus, FTIR spectra of all PUU films were measured, as shown in Figure 3. $\mathrm{N}-\mathrm{H}$ stretching regions in FTIR spectra are too complicate to be analyzed for both DPU and APU films, so the carbonyl stretching regions were examined. The hydrogen bonding between the urea linkages in PUU was observed, as the carbonyl absorption peak of polyester soft segment would affect the absorption peak for urethane group in these systems. It should be pointed out that the carbonyl absorption peak of DMPA unit existing in the PUU macromolecular chain is located at $1550 \mathrm{~cm}^{-1}$, which would not influence the study of hydrogen bonding for urea group [4]. The iteration 
TABLE 4: Assignment of absorption band in urea carbonyl region of FTIR spectra for PUUs.

\begin{tabular}{l|c}
\hline $\begin{array}{l}\text { Wavenumber } \\
\left(\mathrm{cm}^{-1}\right)\end{array}$ & Assignment \\
\hline $1690-1680$ & Free urea carbonyl \\
$1670-1660$ & Disordered I hydrogen-bonded urea carbonyl \\
$1660-1650$ & Disordered II hydrogen-bonded urea carbonyl \\
$1650-1640$ & Ordered I hydrogen-bonded urea carbonyl \\
$1640-1632$ & Ordered II hydroge-bonded urea carbonyl \\
\hline
\end{tabular}

procedure of damping least squares was used to separate the absorption peaks in the carbonyl region [12], corresponding to different kinds of hydrogen bonding (see Table 4), and the curve-fitting results are shown in Table 5. The degree of hydrogen bonding for urea groups $\left(X_{b, \mathrm{UA}}\right)$, the percentage of ordered urea-urea hydrogen bonds $\left(X_{o, \mathrm{UA}}\right)$, and the percentage of disordered urea-urea hydrogen bonds $\left(X_{d, \mathrm{UA}}\right)$ in Table 5 were defined as follows:

$$
\begin{aligned}
X_{b, \mathrm{UA}} & =\frac{\sum \text { Area (bounded) }}{\text { Area }\left(1690-1680 \mathrm{~cm}^{-1}\right)+\sum \text { Area (bounded) }}, \\
X_{0, \mathrm{UA}} & =\frac{\sum \text { Area }\left(1650-1630 \mathrm{~cm}^{-1}\right)}{\text { Area } \left.\left(1690-1680 \mathrm{~cm}^{-1}\right)+\sum \text { Area (bounded) }\right)}, \\
X_{d, \mathrm{UA}} & =\frac{\sum \text { Area }\left(1670-1650 \mathrm{~cm}^{-1}\right)}{\text { Area }\left(1690-1680 \mathrm{~cm}^{-1}\right)+\sum \text { Area (bounded) }} .
\end{aligned}
$$

Table 5 shows that the degree of hydrogen bonding $\left(X_{b, \mathrm{UA}}\right)$ for both kinds of PUU system increases with increasing HS content. Furthermore, $X_{b, \mathrm{UA}}$ for DPU systems is more than that for APU systems containing the same HS content. It is clear that the DPU films should have better ordered structure of HS than the APU films, which is beneficial to well protect the hydrophilic DMPA unit, giving rise to low waterabsorbing amount of the DPU film. For both kinds of PUU film with $4.0 \mathrm{wt} \%$ concentration of DMPA unit, the waterabsorbing amount decreases remarkably with increasing the HS content, as the values of $X_{b, \mathrm{UA}}$ increase obviously. While the HS content in either DPU or APU system is more than $35 \%$, the values of $X_{b \text {,UA }}$ increase only a little bit with increasing both contents of the HS and DMPA unit, because the DMPA unit in HS interferes in the formation of the hydrogen bonding. Thus, the water-resistance ability for both kinds of PUU film decreases with the increase of the HS content.

Analogous hydrogen-bonding behavior but much weaker in the PUU aqueous dispersion could be also expected. In this case, at the same concentration of DMPA unit (4.0 wt \%), the hydrogen bonding as well as the ordered structure of HS in the aqueous dispersion should be enhanced with increasing the HS content, resulting in decreasing the hydrophilic ability of the PUU macromolecular chain and increasing the particle size of the aqueous dispersion (see Table 1). Furthermore, the hydrophilicity of the dispersed particle increases with increasing the DMPA unit content in the PUU system resulting in the decrease of the particle size of the aqueous dispersion.

Figures 4 and 5 show WAXD spectra of DFA, DPU, and APU specimens. Figure 4 exhibits that there are two sharp diffraction peaks at $2 \theta=21^{\circ}$ and $24^{\circ}$ for DFA due to the crystallization of such a polyester polyol. The DPU-25 film with the lowest HS content shows three diffraction peaks at $14^{\circ}, 17^{\circ}$, and $24^{\circ}(2 \theta)$ in Figure 5, and the small peak $24^{\circ}$ $(2 \theta)$ is due to the crystallization of soft segment, whose crystallinity degree is quite low. The other two sharp diffraction peaks at $14^{\circ}$ and $17^{\circ}(2 \theta)$ for DPU-25 system may be attributed to some hydrogen bonding between the hard and soft segments in PUU $[4,5]$. The other DPU films composed of more HS content (more than 25\%) only show a wide peak at around $20^{\circ}(2 \theta)$ indicating that the crystallization of soft segment and the hydrogen bonding between the hard and soft segments are all inhibited resulting from the increase of the HS content in these PUU systems. Thus, for these DPU specimens, the hard segments have difficulty to form the crystals, and only form some ordered structure.

The morphology and the microphase separation of the PUU films can be further characterized by DSC. Figure 6 shows the DSC plots for DFA and different PUU films. The DSC scan results for these specimens are listed in Table 6. Table 6 shows that the DFA has a glass transition temperature $\left(T_{g}\right)$ and two sharp endothermic peaks at around $11^{\circ} \mathrm{C}$ and $37^{\circ} \mathrm{C}$, indicating the presence of some alternative blocks formed with $\mathrm{C}_{36}$-dimer fatty acid/hexylene glycol and adipic acid/hexylene glycol. Similar behavior was found by Kwak et al. [13], who studied a triblock polyol synthesized with poly(tetramethylene oxide) glycol (PTMG) and caprolactone $(\mathrm{CL})$, and they found that such a triblock polyol $\left((\mathrm{CL})_{4.5^{-}}\right.$ PTMG-(CL $\left.)_{4.5}\right)$ showed two melting peaks at around $13^{\circ} \mathrm{C}$ and $40^{\circ} \mathrm{C}$ on DSC plot. All the DPU films have a $T_{g}$ of soft segment, which shifts to higher temperature, compared with that of polyester polyol used $\left(T_{g}=-60^{\circ} \mathrm{C}\right)$, and this indicates some compatibility between the soft and hard segments. Two kinds of endothermic peak were observed in Figure 6 from $90^{\circ}$ to $98^{\circ} \mathrm{C}$ and from $219^{\circ}$ to $227^{\circ} \mathrm{C}$ for DPU films, which should be attributed to the disruption of domains composed of HS with limited short-range order and long-range order, respectively. Table 6 shows that the values of $T_{m 1}, T_{m 2}, \Delta H_{m 1}$, and $\Delta H_{m 2}$ increase with increasing the HS content, confirming that the ordered structure of HS is enhanced with the increase of the HS content. These experimental results are consistent with the FTIR measurements, as discussed previously.

Table 7 lists the surface properties and the water-absorbing amounts of the PBF modified DPU-35 films. For these MPU samples, the contact angle of water increases from $92^{\circ}$ to $100^{\circ}$, and $\gamma_{s}$ decreases from 26.7 to $19.3 \mathrm{mN} / \mathrm{m}$ with an increase in the fluorinated copolymer content. It means that the hydrophobic fluorinated copolymer should be enriched 
TABLE 5: Least-square curve-fitting FTIR spectra in urea carbonyl region of different PUUs.

\begin{tabular}{|c|c|c|c|c|c|c|c|c|c|c|c|c|c|}
\hline \multirow{2}{*}{ Samples } & \multicolumn{5}{|c|}{ Wavenumber $\left(\mathrm{cm}^{-1}\right)$} & \multicolumn{5}{|c|}{ Peak area $(\%)$} & \multirow{2}{*}{$\begin{array}{c}X_{o, \mathrm{U}} \\
\mathrm{A}\end{array}$} & \multirow{2}{*}{$\begin{array}{c}X_{d, \mathrm{U}} \\
\mathrm{A}\end{array}$} & \multirow{2}{*}{$\begin{array}{c}X_{b, \mathrm{U}} \\
\mathrm{A}\end{array}$} \\
\hline & 1 & 2 & 3 & 4 & 5 & 1 & 2 & 3 & 4 & 5 & & & \\
\hline DPU-25 & 1635 & 1647 & 1653 & 1664 & 1686 & 8.7 & 5.8 & 8.7 & 34.0 & 42.8 & 14.5 & 42.7 & 57.2 \\
\hline DPU-31 & 1635 & 1645 & 1653 & 1664 & 1689 & 11.6 & 7.9 & 9.0 & 35.6 & 35.9 & 19.5 & 44.6 & 64.1 \\
\hline DPU-35 & 1635 & 1647 & 1653 & 1664 & 1685 & 13.2 & 5.5 & 12.9 & 41.7 & 26.7 & 18.7 & 54.6 & 73.3 \\
\hline DPU-43 & 1635 & 1645 & 1653 & 1664 & 1689 & 15.5 & 3.6 & 15.5 & 46.3 & 19.1 & 19.1 & 61.8 & 80.9 \\
\hline DPU-50 & 1635 & 1645 & 1653 & 1664 & 1690 & 17.7 & 1.6 & 7.8 & 50.5 & 12.4 & 19.3 & 58.3 & 87.6 \\
\hline APU-25 & 1635 & 1647 & 1653 & 1664 & 1686 & 9.6 & 4.3 & 13.9 & 19.1 & 53.1 & 13.9 & 33.0 & 46.9 \\
\hline APU-31 & 1635 & 1647 & 1653 & 1664 & 1686 & 13.9 & 10.3 & 9.1 & 27.1 & 39.6 & 24.2 & 36.2 & 60.4 \\
\hline APU-35 & 1635 & 1647 & 1653 & 1664 & 1685 & 21.5 & 7.3 & 10.5 & 28.8 & 31.9 & 28.8 & 39.3 & 68.1 \\
\hline APU-43 & 1635 & 1645 & 1653 & 1664 & 1685 & 21.9 & 7.2 & 11.4 & 29.0 & 30.5 & 29.1 & 40.4 & 69.5 \\
\hline APU-50 & 1635 & 1645 & 1653 & 1664 & 1684 & 22.1 & 7.4 & 12.7 & 28.5 & 29.3 & 29.5 & 41.2 & 70.7 \\
\hline
\end{tabular}

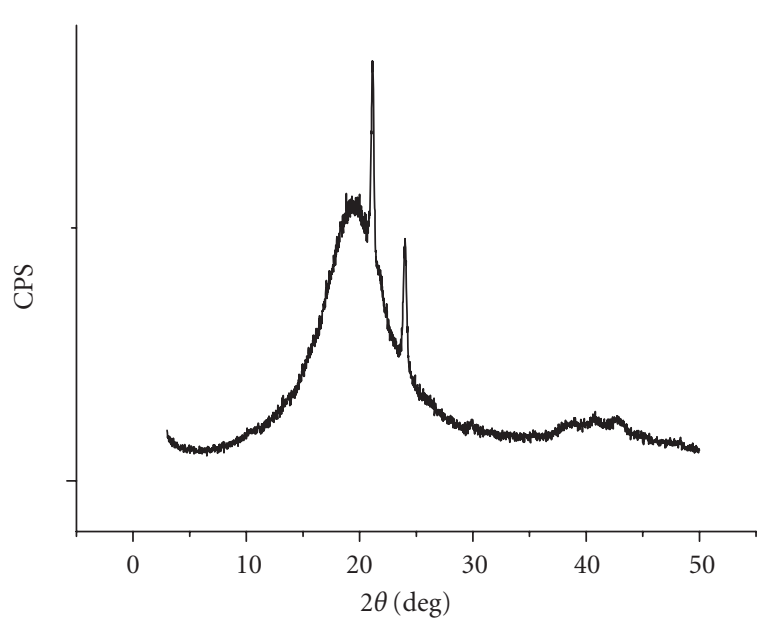

FIgURE 4: WAXD spectra of $\mathrm{C}_{36}$-dimer-fatty-acid-based polyester polyol.

on the surface of the MPU film during the film formation process. The water-absorbing amount of these modified films only increases a little, which may be attributed to the emulsifying agent existing in the PBF emulsion, as discussed before.

During the film formation process, the fluorinated copolymer existing in the waterborne MPU particles and wrapped by the DPU macromolecular chains will be enriched on the surface of the films, but the film forming condition controls the mobility of the fluorinated copolymer. While the film forming temperature is low or the film forming time is short, the MPU film may only approach a quasi-equilibrium state, and much higher temperature or much more time for forming the film would be necessary to reach the thermodynamic equilibrium state. Thus, the effect of temperature on the contact angle of water on the surface of MPU film was observed, as shown in Figure 7. Figure 7 shows that the contact angle of water on the surface of MPU films increases with increasing heat treatment temperature from $60^{\circ} \mathrm{C}$ to $140^{\circ} \mathrm{C}$, resulting from enhancing the migration ability of the fluorinated copolymer. The highest contact angle of water $\left(104^{\circ}\right)$ on the surface of MPU-5 film containing $5.0 \mathrm{wt} \%$ fluorinated copolymer was observed, which is very close to that of the

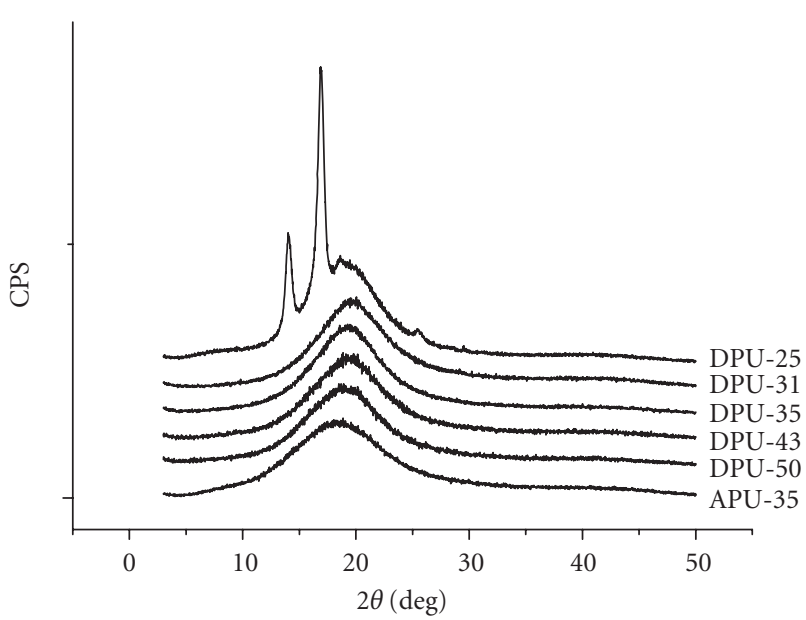

Figure 5: WAXD spectra of different PUU films.

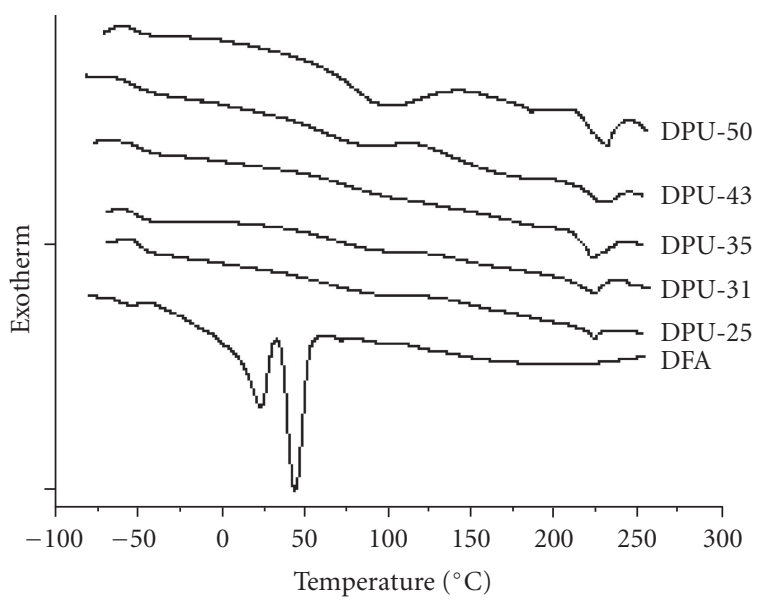

FIgURE 6: DSC curves of DFA and different PUU films.

film prepared only with PBF emulsion $\left(105^{\circ}\right)$, indicating that most of the fluorinated copolymer molecules have been enriched on the surface of the MPU-5 film. 
TABLE 6: DSC scan results for different DPU films. $T_{g}$ of DFA is $-60^{\circ} \mathrm{C}$.

\begin{tabular}{|c|c|c|c|c|c|c|}
\hline Samples & HS content (\%) & $T_{g}\left({ }^{\circ} \mathrm{C}\right)$ & $T_{m 1}\left({ }^{\circ} \mathrm{C}\right)$ & $\Delta H_{m 1}(\mathrm{~J} / \mathrm{g})$ & $T_{m 2}\left({ }^{\circ} \mathrm{C}\right)$ & $\Delta H_{m 2}(\mathrm{~J} / \mathrm{g})$ \\
\hline DPU-25 & 25 & -49 & - & - & 219 & 1.4 \\
\hline DPU-31 & 31 & -51 & - & - & 219 & 4.9 \\
\hline DPU-35 & 35 & -50 & - & - & 218 & 7.3 \\
\hline DPU-43 & 43 & -52 & 90 & 10.8 & 222 & 7.8 \\
\hline DPU-50 & 50 & -50 & 98 & 31.9 & 227 & 9.2 \\
\hline
\end{tabular}

TABLE 7: Some physical properties of modified DPU films.

\begin{tabular}{l|cccccc}
\hline Samples & $\begin{array}{c}\text { Fluorinated } \\
\text { copolymer } \\
\text { content }(\%)\end{array}$ & $\begin{array}{c}\text { Water } \\
\text { absorption } \\
(\text { wt } \%)\end{array}$ & $\begin{array}{c}\text { Contact angle } \\
\text { of water } \\
(\text { degree })\end{array}$ & $\gamma_{s}(\mathrm{mN} / \mathrm{m})$ & $\gamma_{s}^{d}(\mathrm{mN} / \mathrm{m})$ & $\gamma_{s}^{p}(\mathrm{mN} / \mathrm{m})$ \\
\hline DPU-35 & 0 & 1.3 & 87 & 26.7 & 23.8 & 14.7 \\
MPU-1 & 1.0 & 2.1 & 92 & 21.2 & 13.0 & 12.8 \\
MPU-3 & 3.0 & 2.8 & 96 & 19.3 & 10.8 \\
MPU-5 & 5.0 & 3.9 & 100 & 3.4 & 3.3 \\
\hline
\end{tabular}

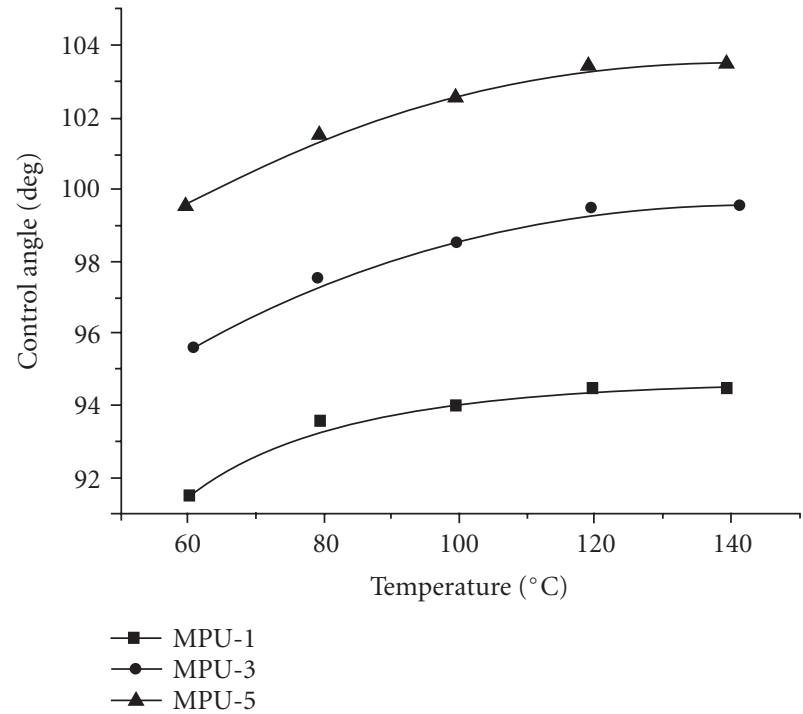

FIgURE 7: Contact angles of water on the surface of MPU films heated at different temperatures for $1 \mathrm{~h}$.

The mechanical properties for all PUU films were measured, as listed in Tables 8 and 9. The DPU films exhibit higher hardness and tensile strength than APU films resulting from the stronger hydrogen bonding in urea carbonyl groups and the more perfect ordered structure of HS in the systems. Table 9 shows that the hardness and the tensile strength of MPU films are enhanced obviously, which should be attributed to the introduction of fluorine atoms and the stronger hydrogen bonding in the system.

In conclusion, a series of the PUU aqueous dispersions was prepared from $\mathrm{C}_{36}$-dimer-fatty-acid-based polyester polyol and characterized. The particle size of $\mathrm{C}_{36}$-DFA-based PUU aqueous dispersion decreased compared with that of the poly-(neopentyl glycol adipate) polyester-polyol-based
TABLE 8: Mechanical properties of different PUU films.

\begin{tabular}{l|cccc}
\hline Samples & $\begin{array}{c}\text { HS } \\
\text { content (\%) }\end{array}$ & Hardness & $\begin{array}{c}\text { Tensile } \\
\text { strength }(\mathrm{MPa})\end{array}$ & $\begin{array}{c}\text { Elongation } \\
\text { at break }(\%)\end{array}$ \\
\hline DPU-25 & 25 & 0.21 & 24.9 & 676 \\
DPU-31 & 31 & 0.30 & 33.6 & 632 \\
DPU-35 & 35 & 0.35 & 48.9 & 527 \\
DPU-43 & 43 & 0.56 & 49.8 & 510 \\
DPU-50 & 50 & 0.67 & 52.2 & 504 \\
APU-25 & 25 & 0.12 & 6.25 & 904 \\
APU-31 & 31 & 0.20 & 12.1 & 707 \\
APU-35 & 35 & 0.26 & 17.3 & 582 \\
APU-43 & 43 & 0.42 & 26.7 & 521 \\
APU-50 & 50 & 0.51 & 35.2 & 492 \\
\hline
\end{tabular}

TABle 9: Mechanical properties of modified DPU films.

\begin{tabular}{l|cccc}
\hline Samples & $\begin{array}{c}\text { Fluorinated } \\
\text { copolymer } \\
\text { content }(\%)\end{array}$ & Hardness & $\begin{array}{c}\text { Tensile } \\
\text { strength }(\mathrm{MPa})\end{array}$ & $\begin{array}{c}\text { Elongation } \\
\text { at break }(\%)\end{array}$ \\
\hline DPU-35 & 0 & 0.35 & 48.9 & 527 \\
MPU-1 & 1.0 & 0.36 & 50.2 & 511 \\
MPU-3 & 3.0 & 0.38 & 53.1 & 507 \\
MPU-5 & 50 & 0.40 & 54.6 & 502 \\
\hline
\end{tabular}

PUU aqueous dispersion. The particle size of fluorinated polyacrylate emulsion modified PUU aqueous dispersions increases compared with the unmodified one. The water resistance and mechanical properties of the $\mathrm{C}_{36}$-DFA-based PUU film are enhanced appreciably resulting from the stronger hydrogen bonding in urea carbonyl groups in the system. The hydrophobicity and the mechanical properties of such PUU films modified with fluorinated polyacrylate emulsion are further enhanced. 


\section{REFERENCES}

[1] B. K. Kim and T. K. Kim, "Aqueous dispersion of polyurethanes from $\mathrm{H}_{12} \mathrm{MDI}$, PTAd/PPG, and DMPA: particle size of dispersion and physical properties of emulsion cast films," Journal of Applied Polymer Science, vol. 43, no. 2, pp. 393-398, 1991.

[2] Y. M. Lee, J. C. Lee, and B. K. Kim, "Effect of soft segment length on the properties of polyurethane anionomer dispersion," Polymer, vol. 35, no. 5, pp. 1095-1099, 1994.

[3] D. J. Hourston, G. Williams, R. Satguru, J. D. Padget, and D. Pears, "Structure-property study of polyurethane anionomers based on various polyols and diisocyanates," Journal of Applied Polymer Science, vol. 66, no. 10, pp. 2035-2044, 1997.

[4] Y. S. Hu, Y. Tao, and C. P. Hu, "Polyurethaneurea/vinyl polymer hybrid aqueous dispersions based on renewable material," Biomacromolecules, vol. 2, no. 1, pp. 80-84, 2001.

[5] D. Y. Yang, C. P. Hu, and S. K. Ying, "Preparation and characterization of waterborne poly(urethane urea) with welldefined hard segments," Journal of Polymer Science Part A: Polymer Chemistry, vol. 43, no. 12, pp. 2606-2614, 2005.

[6] E. Honcoop and E. Appelman, "Polyester polyols for waterresistant polyurethane coatings," in Proceedings of the 30th International Waterborne, High-Solids, and Power Coatings Symposium, New Orleans, La, USA, February 2003.

[7] C. C. Yang, Z. B. Zhang, and C. P. Hu, "Water borne PUA modified with fluorinated polyacrylate microemulsion," China Synthetic Rubber Industry, vol. 28, no. 1, p. 69, 2005.

[8] F. M. Fowkes, "Attractive forces at interfaces," Industrial \& Engineering Chemistry, vol. 56, no. 12, pp. 40-52, 1964.

[9] S. H. Wu, Polymer Interface and Adhesion, Marcel Dekker, New York, NY, USA, 1982.

[10] M. T. Scholz, S. S. Kantner, K. L. Comstock, and C. J. Brown, US Patent: 6,605,666 (2003).

[11] Q. Xu, H. Jing, C. P. Hu, and S. K. Ying, "Particle size and morphology of polyurethaneurea-acrylate aqueous dispersions," Journal of Functional Polymers, vol. 12, no. 4, pp. 405-408, 1999 (Chinese).

[12] N. Luo, D.-N. Wang, and S.-K. Ying, "Hydrogen bonding between urethane and urea: band assignment for the carbonyl region of FTi.r. spectrum," Polymer, vol. 37, no. 14, pp. 30453047, 1996.

[13] Y.-S. Kwak, S.-W. Park, Y.-H. Lee, and H.-D. Kim, "Preparation and properties of waterborne polyurethanes for watervapor-permeable coating materials," Journal of Applied Polymer Science, vol. 89, no. 1, pp. 123-129, 2003. 

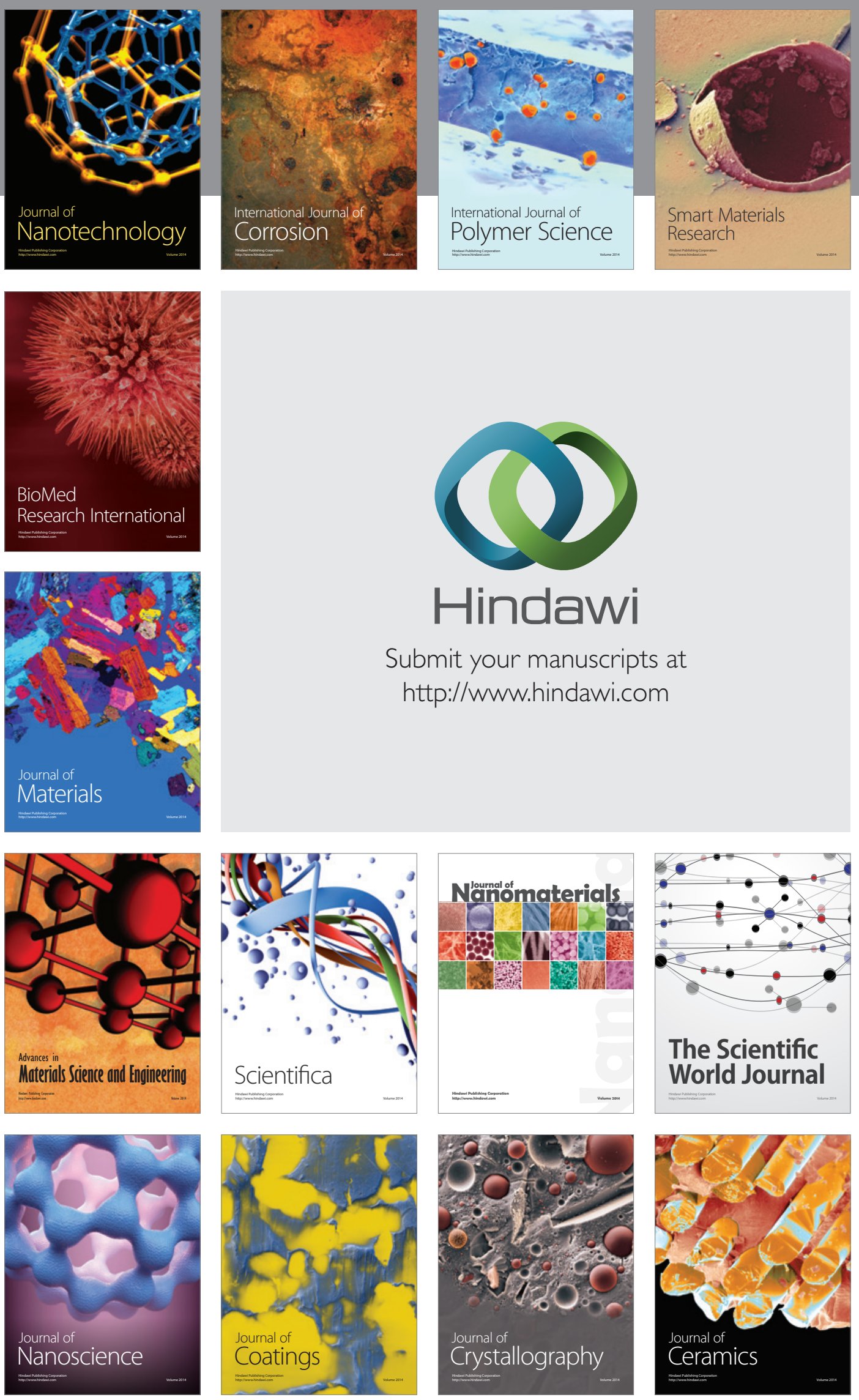

The Scientific World Journal

Submit your manuscripts at

http://www.hindawi.com

\section{World Journal}

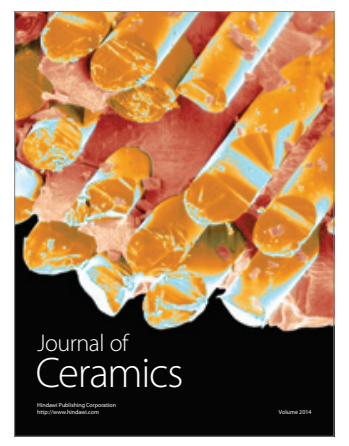

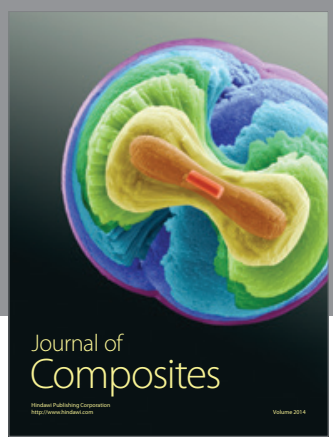
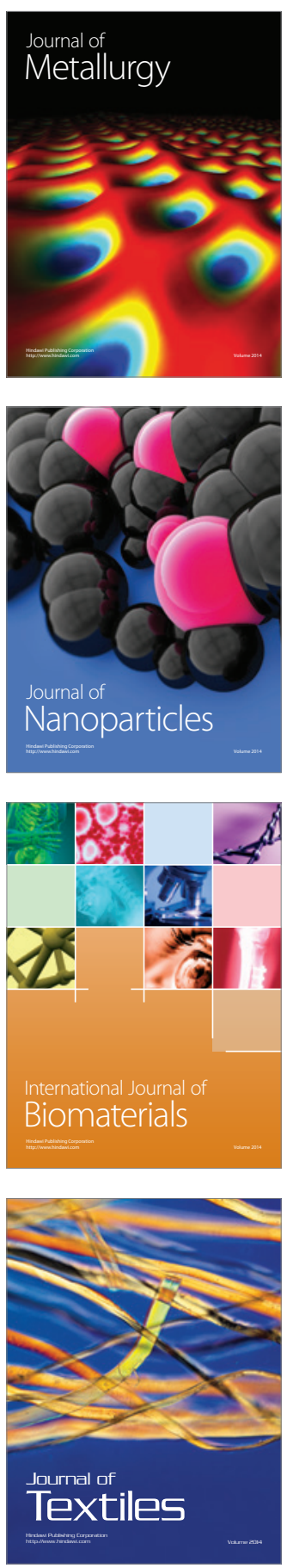